\title{
PENGARUH LATIHAN SKJ 2018 TERHADAP PENINGKATAN KEBUGARAN JASMANI MAHASISWA PUTRI PENJAS UNIB
}

\author{
Intan Soraya \\ Program Studi Pendidikan Jasmani FKIP Universitas Bengkulu \\ Email : Intandsoraya@gmail.com
}

Tono Sugihartono

Universitas Bengkulu

Defliyanto

Universitas Bengkulu

\begin{abstract}
Abstrak
Penelitian ini bertujuan untuk mengetahui pengaruh latihan SKJ 2018 terhadap peningkatan kebugaran jasmani mahasiswa putri Penjas FKIP UNIB secara ilmiah. Dalam penelitian ini mengunakan metode eksperimen semu (quasi eksperimen) dengan desain "One-Group Pretest-Posttest Design", yaitu desain penelitian yang terdapat pretest sebelum diberi perlakuan dan posttest setelah diberi perlakuan. Populasi dalam penelitian ini adalah mahasiswa putri penjas UNIB yang berjumlah 75 orang pada tahun 2019 dan Sampel penelitian ini berjumlah 30 orang. Analisis statistik yang digunakan dalam penelitian ini adalah Uji t untuk menguji hipotesis bahwa ada pengaruh latihan SKJ 2018 terhadap peningkatan kebugaran jasmani mahasiswa putri penjas UNIB. Hasil analisis perhitungan Uji t ternyata terdapat pengaruh yang signifikan terhadap hasil kebugaran jasmani. Hasil perhitungan menyatakan bahwa tes akhir dengan perolehan perhitungan nilai thitung $1,882>$ $t_{\text {tabel }} 1,701$ dengan taraf $\alpha=0,05$ artinya ada pengaruh yang signifikan antara $X$ (latihan SKJ 2018) dengan $Y$ (peningkatan kebugaran jasmani) dengan presentase peningkatan sebesar 49,28\%. Berdasarkan dari hasil pengujian hipotesis yang telah dilakukan sebelumnya menyatakan bahwa ada pengaruh yang signifikan antara latihan SKJ 2018 terhadap peningkatan kebugaran jasmani mahasiswa putri penjas UNIB.
\end{abstract}

Kata Kunci: Latihan SKJ 2018, Peningkatan Kebugaran Jasmani

\begin{abstract}
This study aims to determine the effect of scientific SKJ 2018 training on improving physical fitness of Penjas female students of FKIP UNIB. In this study using quasi-experimental methods with the design of "One-Group Pretest-Posttest Design", namely the design of the study that had a pretest before being treated and posttest after being treated. The population in this study were 75 female students from the UNIB penjas in 2019 and the sample of the study was 30 people. The statistical analysis used in this study is the test to test the hypothesis that there is an effect of SKJ 2018 training on improving physical fitness of UNIB female students. The results of the analysis of the t-test calculations showed that there was a significant effect on the results of physical fitness. The calculation results state that the final test with the calculation of the tcount of 1.882> t table 1.701 with the level of $\alpha$ $=0.05$ means that there is a significant influence between $X$ (SKJ 2018 training) with $Y$
\end{abstract}


(increasing physical fitness) with an increase percentage of $49.28 \%$. Based on the results of hypothesis testing that has been done previously stated that there is a significant influence between the SKJ 2018 training on improving physical fitness of female students in the UNIB field.

Keywords: SKJ 2018 Exercises, Improvement of Physical Fitness

\section{PENDAHULUAN}

Olahraga merupakan salah satu bentuk kegiatan fisik dan banyak dilakukan oleh berbagai kalangan masyarakat, dari mulai anak-anak, remaja, dewasa, baik laki-laki maupun perempuan. Menurut Santosa Giriwijoyo \& Dikdik Zafar.S (2013: 36), Olahraga adalah budaya manusia, artinya tidak dapat disebut kegiatan olahraga apabila tidak ada faktor mansia yang berperan secara ragawi/pribadi melakukan aktivitas olahraga itu. Salah satu alasan mahasiswa melakukan olahraga adalah mahasiswa mendapatkan kesegaran jasmani dari aktivitas olahraga tersebut yang berpengaruh terhadap kesehatan tubuh sehingga mahasiswa bisa melakukan kegiatan lain dengan lebih baik. Olahraga juga dimaksudkan untuk pencapaian prestasi bagi mahasiswa yang menggelutinya.

Kesegaran jasmani berfungsi mengembangkan kesanggupan kerja bagi siapapun, sehingga dapat menyelesaikan tugas dengan baik tanpa mengalami kelelahan yang berarti. Fungsi kesegaran jasmani semakin jelas, karena sukar mencapai prestasi yang baik tanpa disertai jasmani yang segar dalam semua aktivitas untuk mewujudkan suatu hasil yang memuaskan.

Tuntutan akan kebugaran jasmani setiap orang berbeda. Perbedaan itu biasanya dipengaruhi oleh jenis pekerjaan masing-masing.
Bagi mahasiswa, kebugaran jasmani diperlukan untuk belajar, kuliah atau kegiatan yang mendukung perkuliahan. Oleh karena itu setiap mahasiswa hendakya memiliki kebugaran jasmani yang baik guna mendukung dan memperlancar aktivitas perkuliahannya. Terlebih bagi mahasiswa Program Studi Penjas yang hampir setiap hari harus mengikuti perkuliahan praktek maupun teori, selain harus memiliki bakat dan minat yang baik, juga dituntut memiliki kebugaran jasmani yang memadahi, selain itu juga dituntut memiliki kesehatan yang prima. Kebugaran jasmani dan kesehatan diperlukan mahasiswa untuk mempertinggi kemampuan belajar dan menyelesaikan tugastugas lainnya.

Aktivitas tersebut pada dasarnya merupakan sarana aktivitas jasmani yang sistematis dan terencana yang bertujuan untuk meningkatkan serta memelihara kebugaran jasmani. Menurut Cindo (2010 : 4) tujuan senam adalah untuk mendapatkan kekuatan dan keindahan jasmani. Senam SKJ 2018 merupakan senam yang didaur ulang dari senam SKJ 1984 yang fenomenal.

Program Studi Penjas merupakan salah satu program studi yang ada di FKIP Universitas Bengkulu, dan merupakan program studi yang sudah memiliki akreditasi B. Sebagian besar mahasiswa Program Studi Penjas berasal dari 
kalangan atlet, namun tidak semua mahasiswa Program Studi Penjas mempunyai tubuh yang bugar dan sehat. Terbukti dari data hasi tes kebugaran jasmani mahasiswa penjas semester VI angkatan 2016 pada saat mengikuti mata kuliah tes dan pengukuran, hasil rata-rata tes daya tahan aerobik masih dalam kategori 'kurang'. Mahasiswa Program Studi Penjas termasuk Program Studi di FKIP Universitas Bengkulu yang mempunyai prestasi olahraga yang dengan kategori cukup baik. Prestasi olahraga tersebut dicapai dari cabang olahraga bola voli, futsal, atletik, senam ataupun cabang olahraga lainnya. Program Studi Penjas selalu mengikutsertakan mahasiswa atau atletnya untuk bertanding ataupun menjadi wasit dan juga berpartisipasi sebagai panitia perlombaan atau pertandingan.

Peneliti mengamati bahwa mahasiswa Program Studi Penjas masih kurang menyadari akan manfaat dari Senam Kebugaran Jasmani, terbukti bahwa pada saat kegiatan senam rutin setiap hari Jumat masih banyak mahasiswa yang tidak mengikuti kegiatan tersebut karena terlambat, tidak hafal gerakan, malas dan faktor lainnya. Oleh karena itu peneliti tertarik untuk mengetahui bagaimana senam SKJ 2018 dapat dimanfaatkan secara maksimal supaya tujuan dari kegiatan tersebut dapat tercapai dan harapannya kebugaran jasmani mahasiswa meningkat. Latihan senam SKJ 2018 ini sangat bermanfaat apabila dilakukan secara rutin dan teratur. Manfaat yang paling utama yaitu dapat melatih daya tahan dan secara tidak langsung akan membina sikap kedisiplinan. Dengan mengikuti kegiatan latihan secara rutin dan teratur maka akan menjadikan kegiatan tersebut sebagai suatu kebiasaan bagi mahasiswa. Namun tujuan yang paling utama adalah meningkatkan kebugaran jasmani mahasiswa Program Studi Penjas. Untuk memberikan bukti tentang pengaruh latihan Senam Kebugaran Jasmani 2018 terhadap Peningkatan Kebugaran Jasmani Mahasiswa Putri Penjas FKIP Universitas Bengkulu maka akan dilakukan penelitian dan pengkajian secara mendalam.

Berdasarkan latar belakang yang telah di uraikan di atas, peneliti tertarik untuk melakukan penelitian dengan judul "Pengaruh Latihan SKJ 2018 terhadap Peningkatan Kebugaran Jasmani Mahasiswa Putri Penjas UNIB".

\section{METODE}

Jenis penelitian ini adalah eksperimen. Penelitian ini menggunakan desain penelitian preexperimental design. Desain ini belum merupakan eksperimen sungguh-sungguh karena masih terdapat variabel luar yang ikut berpengaruh terhadap terbentuknya variabel dependen (Sugiyono, 2016: 74). Menurut Suharsimi Arikunto dalam Zainul Arifin (2018: 27), penelitian eksperimen merupakan penelitian yang bertujuan mengetahui akibat yang terjadi pada 
subjek penelitian setelah diberi suatu tindakan atau perlakuan.

Desain penelitian yang digunakan dalam penelitian ini adalah "OneGroup Pretest-Posttest Design", yaitu desain penelitian yang terdapat pretest sebelum diberi perlakuan dan posttest setelah diberi perlakuan. Dengan demikian dapat diketahui lebih akurat, karena dapat membandingkan dengan diadakan sebelum diberi perlakuan. Dalam hal ini yang akan diteliti adalah upaya meningkatkan kebugaran jasmani mahasiswa putri Penjas UNIB melalui latihan SKJ 2018.

Populasi adalah wilayah generalisasi yang terdiri atas: objek/subyek yang menpunyai kualitas dan karakteristik tertent yang diterapkan oleh peneliti ntuk dipelajari dan kemudian ditarik kesimpulannya (Sugiyono, 2016 : 80). Populasi dalam penelitian ini adalah seluruh mahasiswa putri Penjas UNIB yang berjumlah 75 orang dengan rincian semester II berjumlah 23 orang, semester IV berjumlah 22 orang, semester VI berjumlah 13 orang dan semester VIII berjumlah 17 orang. Sampel yang digunakan adalah Random Sampling. Sampel dari penelitian ini adalah sebanyak 30 orang mahasiswa putri Penjas Unib.

Instrumen penelitian adalah alat pengumpul data dalam suatu penelitian (Dian Pujianto \& Bayu Insanistyo, 2013:61). Instrumen yang digunakan dalam penelitian ini tes Cooper lari 12 menit. Tes ini bertujuan untuk mengukur kemampuan dan kesanggupan kerja fisik seseorang.

\section{HASIL DAN PEMBAHASAN}

HASIL

Berdasarkan

distribusi presentase tes dapat di deskripsikan bahwa hasil pre tes lari 12 menit dari 30 mahasiswa sebanyak 3 orang (10\%) dalam kategori menempuh jarak $1,40-1,56$. Sebanyak 5 orang $(16,7 \%)$ dalam kategori menempuh jarak $1,57-1,73$. Sebanyak 7 orang $(23,3 \%)$ dalam kategori menempuh jarak $1,74-1,90$. Sebanyak 8 orang $(26,7 \%)$ dalam kategori menempuh jarak 1,91-2,07. Sebanyak 6 orang (20\%) dalam kategori menempuh jarak 2,08-2,24, dan hanya 1 orang saja (3\%) dalam kategori menempuh jarak 2,25 - 2,41.

Tabel 1. Distribusi Frekuensi Hasil Pre tes Lari 12 Menit

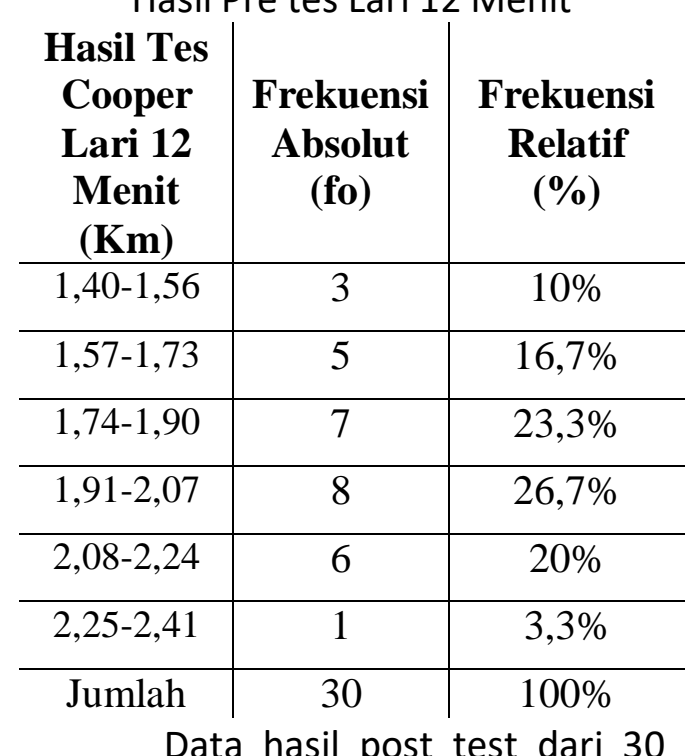

mahasiswa sebanyak 5 orang $(16,7 \%)$ dalam kategori menempuh jarak 1,58-1,72. Sebanyak 4 orang $(13,3 \%)$ dalam kategori menempuh jarak 1,73-1,87. Sebanyak 5 orang $(16,7 \%)$ dalam kategori menempuh 
jarak 1,88-2,02. Sebanyak 4 orang $13,3 \%$ dalam kategori menempuh jarak 2,03-2,17. Sebanyak 5 orang $16,7 \%$ dalam kategori menempuh jarak 2,18-2,32, dan 7 orang (23,3\%) dalam kategori menempuh jarak 2,33-2,47.

Tabel 2. Distribusi Frekuensi Hasil

\begin{tabular}{|c|c|c|}
\hline \multicolumn{3}{|c|}{ Post Test Lari 12 Menit } \\
\hline $\begin{array}{c}\text { Hasil Tes } \\
\text { Cooper } \\
\text { Lari } 12 \\
\text { Menit } \\
(\text { Km) } \\
\end{array}$ & $\begin{array}{l}\text { Frekuensi } \\
\text { Absolut } \\
\text { (fo) }\end{array}$ & $\begin{array}{c}\text { Frekuensi } \\
\text { Relatif } \\
(\%)\end{array}$ \\
\hline $1,58-1,72$ & 5 & $16,7 \%$ \\
\hline $1,73-1,87$ & 4 & $13,3 \%$ \\
\hline $1,88-2,02$ & 5 & $16,7 \%$ \\
\hline $2,03-2,17$ & 4 & $13,3 \%$ \\
\hline $2,18-2,32$ & 5 & $16,7 \%$ \\
\hline $2,33-2,47$ & 7 & $23,3 \%$ \\
\hline Jumlah & 30 & $100 \%$ \\
\hline
\end{tabular}

terhadap variabel kebugaran jasmani untuk pre test dan post test memberikan hasil bahwa kebugaran jasmani berdistribusi normal (Lhitung= 0,0852), sedangkan untuk post test memberikan hasil bahwa kebugaran jasmani berdistribsi normal (Lhitung $=0,111$ ).

Tabel 3. Hasil Uji Normalitas Data

\begin{tabular}{|c|c|c|}
\hline \multicolumn{2}{|c|}{$\begin{array}{c}\text { Uji Normalitas } \\
\text { Data }\end{array}$} & Keterangan \\
\hline Pre Test & 0,0852 & Normal \\
\hline Post Test & 0,111 & Normal \\
\hline
\end{tabular}
bahwa hasil pengujian normalitas data memiliki skor Lhitung lebih kecil dari Ltabel dengan $n=30$ sedangkan $L_{\text {tabel }}$ pada taraf signifikan $\alpha=0,05$ diperoleh 0,161.
Dari perhitungan Uji homogenitas data didapat nilai $F_{\text {hitung }}$ sebesar 1,35 sedangkan nilai $F_{\text {tabel }}$ (dilampiran) pada taraf signifikan $5 \%$ dengan $\mathrm{dk}=(\mathrm{b}),(\mathrm{n}-1)=(30-1)=29$, dimana 1 sebagai pembilang dan 29 sebagai penyebut adalah sebesar 4,18. Fhitung $<F_{\text {tabel }}$ yaitu $1,35<4,17$ ini berarti tidak terdapat perbedaan varians dari masing-masing variabel atau harga variansnya Homogen.

Hasil uji $t$ terhadap kebugaran jasmani diketahui bahwa kebugaran jasmani terdapat pengaruh signifikan dengan $t_{\text {hitung }}>$ $t_{\text {tabel }}$ yaitu 1,882 > 1,701.

\section{PEMBAHASAN}

Penelitian yang telah dilakukan menunjukkan bahwa kebugaran jasmani mahasiswa putri Penjas UNIB sebanyak 30 orang pada pengukuran awal (pre test) kebugaran jasmani terendah 1,40 $\mathrm{km}$ dan kebugaran jasmani tertinggi dengan jarak $2,40 \mathrm{~km}$ sedangkan rata-rata 1,88. Pengukuran akhir (post test) kebugaran jasmani terendah $1,58 \mathrm{~km}$ dan kebugaran jasmani tertinggi dengan jarak 2,24 sedangkan rata-rata 2,04. Berdasarkan hasil penelitian yang telah dilakukan nilai rerata kebugaran jasmani sebelum perlakukan dan setelah perlakuan terdapat peningkatan. Latihan SKJ 2018 memberikan kontribusi daya tahan kardiovaskuler, intensitas latihan meningkat selama 16 kali pertemuan. sehingga kebugaran jasmani meningkat. Rangkaian gerakan dari senam SKJ 2018 juga memberikan kontribusi untuk 
melatih kekuatan otot, daya tahan, kelincahan dan keseimbangan. Dalam memberikan perlakuan dengan latihan SKJ 2018 selama 16 kali pertemuan selama 1 bulan lebih 1 minggu dengan 3 kali/ minggu, kebugaran jasmani terjadi peningkatan sebesar $49,28 \%$. Untuk menentukan kebugaran jasmani mahasiswa salah satu bentuk tes yang digunakan adalah tes Cooper (lari 12 menit). Bentuk tes ini mempunyai beberapa kelebihan, diantaranya data diperoleh valid dan dapat dilaksanakan secara massal.

Dari hasil post test dalam perlakuan latihan SKJ 2018 dapat diketahui seberapa besar nilai kebugaran jasmani dan termasuk dalam klasifikasi kurang sekali, kurang, sedang, baik dan baik sekali untuk mahasiswa putri penjas unib. Dari 30 orang secara keseluruhan dalam klasifikasi baik. Kebugaran jasmani yang termasuk dalam klasifikasi baik sekali sebanyak 7 orang, klasifikasi baik sebanyak 9 orang, klasifikasi sedang 4 orang, klasifikasi kurang 9 orang, dan klasifikasi kurang sekali sebnayak 1 orang. Dilihat dari prosentase ratarata pre test menuju post test terjadi peningkatan secara signifikan sebesar $49,28 \%$.

Berdasarkan dari hasil pengujian hipotesis yang telah dilakukan sebelumnya menyatakan $\mathrm{H}_{\mathrm{o}}$ ditolak dan $\mathrm{H}_{\mathrm{a}}$ diterima sehingga ada pengaruh latihan SKJ 2018 terhadap peningkatan kebugaran jasmani mahasiswa putri Penjas UNIB. Dapat disimpulkan bahwa semakin sering melakukan latihan tersebut maka semakin baik pula peningkatan kebugaran jasmani mahasiswa tersebut.

\section{PENUTUP}

\section{SIMPULAN DAN SARAN}

Berdasarkan pada uraian hasil pembahasan dalam penelitian ini serta dari pengolahan data yang telah dilakukan maka dapat diambil kesimpulan bahwa :

Hipotesis yang diajukan diterima, yaitu adanya pengaruh latihan SKJ 2018 terhadap peningkatan kebugaran jasmani mahasiswa putri Penjas UNIB. Dengan perhitungan statistik uji $t$ dimana $t_{\text {hitung }} 1,882>t_{\text {tabel }} 1,701$ pada taraf signifikan $\alpha=0,05$. Dengan persentase peningkatan kebugaran jasmani sebesar 49,28\% dapat disimpulkan bahwa terdapat pengaruh latihan SKJ 2018 terhadap peningkatan kebugaran jasmani mahasiswa putri Penjas UNIB.

Berdasarkan hasil penelitian yang telah dilakukan, peneliti berharap dan memberikan saran sebagai berikut :

1. Sehubungan dengan penelitian ini, maka diharapkan bagi pembina, pelatih dan guru penjas agar dapat terus memperhatikan dan memberi latihanlatihan dengan variasi terbaru yang berguna untuk meningkatkan kesehatan dan kebugaran jasmani sebagai salah satu penunjang dalam proses pembelajaran. 
2. Para mahasiswa khususnya mahasiswa penjas agar lebih memperhatikan dan meningkatkan kualitas kebugaran jasmaninya

3. Peneliti lain disarankan untuk dapat mengkaji bentuk latihan kebugaran jasmani yang lainnya yang berhubungan dengan kebugaran jasmani.

4. Peneliti menyadari bahwa masih banyak kekurangan dalam penelitian ini. Untuk meningkatkan kebugaran jasmani dengan melakukan latihan SKJ 2018 membutuhkan proses yang lama untuk memperoleh hasil yang maksimal. Oleh karena itu untuk meningkatkan kebugaran jasmani dengan latihan SKJ 2018 harus dengan latihan yang rutin dengan jangka waktu latihan yang lebih lama > dari 16 kali latihan untuk memperoleh hasil yang lebih baik.

\section{DAFTAR PUSTAKA}

Cindo, Morena. 2010. Jenis-Jenis Senam. Jakarta: Trans Mandiri Abadi.

Giriwijoyo, Santosa \& Sidik, D.Z, 2013. Ilmu Faal Olahraga (Fisiologi Olahraga) Fungsi Tubuh Manusia pada Olahraga Untuk Kesehatan dan Prestasi. Bandung: PT Remaja Rosdakarya.

Sugiyono. 2016. Metode Penelitian Kuantitatif, Kualitatif, dan $R$ \& $D$. Bandung: Alfabeta.

Arifin, Zainul. 2018. Pengaruh Latihan Senam Kebugaran Jasmani (SKJ) Terhadap Tingkat Kebugaran Siswa Kelas $V$ di MIN Donomulyo Kabupaten Malang, Journal of Education, Vol.1 (1) hal. 22

Pujianto, Dian \& Insanistyo, Bayu. 2013. Dasar-Dasar Penelitian Pendidikan Jasmani. Bengkulu: Universitas Bengkulu

Soni, Tono, dan Yarmani. 2017. "Kontribusi Kelentukan Pinggang dan Power Otot Lengan Pada Keterampilan Stutz Senam Lantai". Jurnal Kinestetik, Vol. 1 (1).

Yeyen Sari, Dian, dan Bayu. 2018. "Pengaruh Metode Bermain Terhadap Hasil Belajar Senam Lantai Roll Belakang Pada Siswa Kelas VIII SMP Negeri 4 Bengkulu". Jurnal Kinestetik, Vol. 2 (1). 